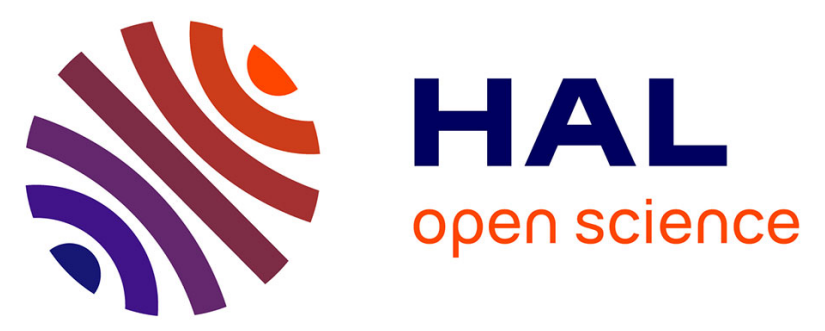

\title{
Previous Drug Exposure in Patients Hospitalised for Acute Liver Injury: A Case-Population Study in the French National Healthcare Data System
}

Nicholas Moore, Stephanie Duret, Adeline Grolleau, Régis Lassalle, Vanessa Barbet, Mai Duong, Nicolas Thurin, Cécile Droz-Perroteau, Sinem Ezgi Gulmez

\section{To cite this version:}

Nicholas Moore, Stephanie Duret, Adeline Grolleau, Régis Lassalle, Vanessa Barbet, et al.. Previous Drug Exposure in Patients Hospitalised for Acute Liver Injury: A Case-Population Study in the French National Healthcare Data System. Drug Safety, In press, 10.1007/s40264-018-0752-1 . hal-01938556

\section{HAL Id: hal-01938556 https://hal.science/hal-01938556}

Submitted on 28 Nov 2018

HAL is a multi-disciplinary open access archive for the deposit and dissemination of scientific research documents, whether they are published or not. The documents may come from teaching and research institutions in France or abroad, or from public or private research centers.
L'archive ouverte pluridisciplinaire HAL, est destinée au dépôt et à la diffusion de documents scientifiques de niveau recherche, publiés ou non, émanant des établissements d'enseignement et de recherche français ou étrangers, des laboratoires publics ou privés. 
Previous drug exposure in patients hospitalized for acute liver injury: a case-population study in the French national healthcare data system.

Running title: Drug-induced acute liver injury

Nicholas Moore $(1,2,3) *$, Stephanie Duret (1, 2), Adeline Grolleau (1), Regis Lassalle (1), Vanessa Barbet (1), Mai Duong (1), Nicolas Thurin (1, 2), Cécile Droz-Perroteau (1), Sinem Ezgi Gulmez (1)

(1) Bordeaux PharmacoEpi, INSERM CIC1401, Université de Bordeaux, Bordeaux;

(2) Bordeaux University Hospital, Bordeaux, France;

(3) INSERM U1219, Bordeaux, France.

* Corresponding author:

Nicholas Moore

Bordeaux PharmacoEpi, INSERM CIC1401, Case 41 - Bâtiment du Tondu, 146 rue Léo Saignat, 33076 Bordeaux Cedex, France.

nicholas.moore@u-bordeaux.fr

Tel: +33 (0)5 57574675

Word count, Abstract: 293

Word count, main text (excluding the title page, abstract, references, tables, figures): 4,083

Number of Tables: 2

Number of Figures: 3 


\section{Authors contributions}

The present paper is a product of the EPIHAM Project that was submitted for public funding by the Bordeaux PharmacoEpi research Team, and served as support for the Eu2P $\mathrm{PhD}$ project of Prof Sinem Ezgi Gulmez. Prof Nicholas Moore had the original idea and supervised the project. Cécile Droz-Perroteau was the chief operating officer, discussed the study background and coordinated study logistics. Adeline Grolleau was the operational study manager, and collaborated to draft the manuscript. Régis Lassalle was the chief statistician and data manager. Vanessa Barbet and Mai Duong provided data-management and statistical analyses. Nicolas Thurin is a scientific adviser, and he contributed to the selection algorithm of the cases. Stéphanie Duret developed this specific analysis, collaborated to draft the manuscript.

All authors contributed comments and approved the final version of this paper. 


\section{Key Points:}

- Liver Injury and in particular Acute Liver Injury (ALI) is an important source of druginduced regulatory action, drug-induced hospital admissions and burden of care.

- studies based on clinical identification of hospitalized cases rarely include more than a few hundred cases.

- The EPIHAM study provides information on the drugs associated with the greatest burden of ALI, and drugs with the highest individual associated risk, over the whole French population over 5 years. Most of these drugs are well known to be able to cause liver injury. 


\begin{abstract}
Introduction: Acute liver injury (ALI) is a major reason for stopping drug development or removing drugs from the market. Hospitalisation for ALI is relatively rare for marketed drugs, justifying studies in large-scale databases such as the nationwide Système National des Données de Santé (SNDS) that covers 99\% of the French population

Methods: SNDS was queried over 2010-2014 for all hospital admissions for acute toxic liver injuries not associated with a possible other cause, using a case-population approach. Exposures of interest were drugs dispensed from 7 to 60 days before date of admission. Individual drugs were analysed by their frequency (if $\geq 5$ cases), and by the ratio of exposed cases to the number of exposed subjects and to exposed patient-time in the general population over the same time-frame.
\end{abstract}

Results: Over 5 years, 4,807 cases of ALI were identified, mean age 54.5, 59\% women, 76\% exposed to at least one of 249 different drugs. Drugs most commonly identified were nonoverdose paracetamol (31\% of cases), esomeprazole or omeprazole (18\%), phloroglucinol, domperidone, coamoxiclav, furosemide, atorvastatin (more than 250 cases each). When compared to population exposures, the highest per-person risks were observed with antimycobacterial antibiotics with 1 case for 1,000 or fewer users, followed by colestyramine and erythromycin (around 1/5,300), antiepileptic drugs, anticoagulants, anti-Alzheimer drugs $(1 / 6,000-1 / 10,000$ users). When a person-time approach is considered, the drugs with the highest per-tablet risk were still the antituberculosis drugs followed by a number of other antibiotics.

Conclusions: This nationwide study describes drugs associated with ALI, according to absolute population burden, to per-patient and per-tablet risk. Some of these associations may be spurious, others causal, and others yet were unexpected. Systematic analysis of drug classes will look for outliers within each class that could raise signals of unexpected hepatic toxicity.

Keywords: Acute liver injury, case-population, drug exposure, claims database, pharmacoepidemiology. 


\section{Introduction}

Liver Injury and in particular Acute Liver Injury (ALI) associated with medicines (druginduced liver injury (DILI)) is a major source of regulatory action, of hospital admissions and burden of care [1-7]. Many drugs have been shown to cause or are suspected of causing liver injury, such as paracetamol, anti-mycobacterial drugs, erythromycin, or Valproic acid [8-10]. DILIs can range from simple elevation of liver enzymes, to acute liver failure leading to death or liver transplantation $[11,12]$. A previous European study (SALT) of acute liver failure leading to liver transplantation (ALFT) in 7 countries over 3 years and confirmed that many drugs are involved in ALFT [1-3, 13]. The majority of the DILIs are not just acute liver failure or necrosis resulting in transplantation, but result in hospital admissions for ALI.[9]. Studies based on clinical identification of hospitalized cases often concern only a few hundred cases [14-16]. A study conducted in Thailand in the nationwide hospital admission database identified 6515 patients hospitalized with drug-induced liver injury, or drug intoxications (using the ICD-10 codes K71 and T36-T65), among which 33.5\% were acute hepatitis [17]. This study confirmed well-known associations but also some unexpected ones. A preliminary study in the French Claims database $1 / 97^{\text {th }}$ sample EGB confirmed the feasibility of such a study, but also the need of accessing the full Système National des Données de Santé (SNDS) database that includes $99 \%$ of the French population $[18,19]$.

EPIHAM (epidemiology of acute liver injury from medicines), the study described here, identified all hospital admissions for ALI in SNDS over 5 years, not related to acute drug overdose or other clinical causes. Exposures identified from drug dispensing in these patients were compared to drug utilisation in EGB, using the case-population approach $[2,20]$. From these data, we identified the drugs most often associated with ALI, and those with the highest apparent risk. 


\section{Material and Methods}

This was a case-population study in the French National Healthcare System Claims Database.

\subsection{Data sources}

This study was done in the Système National des Données de Santé, (SNDS), and its random permanent representative $1 / 97^{\text {th }}$ sample, Echantillon Généraliste de Bénéficiaires (EGB). SNDS currently includes 66.6 million people (99\% of the French population) [19]. SNDS (and its sample, EGB) contains information on (i) general demographics (gender, year of birth, region of residence, date of death but not cause of death), (ii) outpatient healthcare claims, with dates and codes for medical and other healthcare professionals visits, medical procedures, lab tests and other exams (but not results), drugs and medical devices, (iii) registration for a list of 30 long-term diseases (LTD) and their associated International Classification of Diseases $10^{\text {th }}$ revision (ICD-10) codes allowing patients to receive full reimbursement for expenditure related to LTD, and (iv) hospital discharge data, which include start and end dates for all medical, obstetric and surgery hospitalizations, medical procedures, cost coding system, and the medical unit data when the patient is hospitalized successively in several medical units. The hospital discharge summary includes ICD-10 codes for main, related and associated diagnoses for all hospitalizations. The main diagnosis is the health problem that motivated the admission in the hospital, determined at hospital discharge. The related diagnoses exist if the main diagnosis is a procedure for a chronic or LTD disease and indicates the disease at the origin of the procedure. The associated diagnoses represent specific healthcare status modifiers, mainly underlying chronic diseases [21]. Hospital discharge ICD-10 codes are based on definitions. They are routinely coded by the physicians in charge of the patient, based on clinical data, assisted by trained professional medical information technicians who verify the codes to ensure consistency, with national 
coding instructions and manuals. The medical information departments in the hospitals that are in charge of the quality of the coding conduct random validation checks on the diagnostic codes that are used, in addition to training programmes. This is part of the National accreditation and certification process for the Hospitals that includes the completeness and exactitude of the coding process. [22] The national Healthcare insurance system, which pays the hospitals and clinics based on disease or diagnosis-related groups (DRG) regularly audits these codes and may levy large fines in the case of discrepancies. Certain individual diagnoses have also been subject to validation studies, such as heart failure, stroke, coronary heart disease, or other diseases, which have found positive predictive values around $70-90 \%$ [21, 23-26], consistent with the national effort at coding quality.

\subsection{Study design}

The EPIHAM study was a case-population study in a claims database [19]. This approach consists in the comparison of exposure rates to a given drug in subjects presenting an event of interest (cases) with the exposure rate in the source population (reference population), as previously described [20, 27-29].

\subsection{Definition of cases}

Cases of ALI were identified and extracted over 5 years from SNDS, defined as patients aged 18 years and over with a first hospital admission for Acute Liver Injury (ALI) between 1 January 2010 and 31 December 2014. The date of first admission for ALI was considered as the index date. Hospitalization for ALI was defined as hospitalization with a main diagnosis ICD-10 code for acute toxic liver injury (K71.1, K71.2, K71.6, K71.9) or hepatic failure (K72.0), without previous hospitalization for ALI. If a patient had several hospitalisations for ALI over the study period, only the first was considered. 
Exclusion criteria included:

- Any diagnosis code for non-drug-related liver disease or potential liver injury during the hospitalization of interest or in the previous 60 days as identified by the ICD-10 codes for associated, related or main diagnosis: chronic viral hepatitis (B18), malignant neoplasms (all $\mathrm{C}$ codes), mental and behavioural disorders due to use of alcohol (F10), other degenerative diseases of nervous system, not elsewhere classified (G31), heart failure (I50), portal vein thrombosis (I81), oesophageal varices (I85), alcoholic liver disease (K70), fibrosis and cirrhosis of liver (K74), other diseases of liver (K76), cholelithiasis (K80), other diseases of biliary tract (K83), ascites (R18), presence of cardiac and vascular implants and grafts (Z95), liver transplant failure and rejection (T86.4))

- Hospitalization with a diagnosis of liver transplant status in the previous 60 days (ICD-10 code for associated, related or main diagnosis: Z94.4);

- A diagnosis of poisoning during the hospitalization of interest and the concomitant stays (ICD-10 code for associated, related or main diagnosis: from T36 to T50).

Patients with at least one of the following criteria were also excluded from the analysis:

- Patients without health care usage, or not affiliated to the national healthcare insurance system during the year before hospitalization for ALI,

- Patients with no history or less than 60 days of history in the database before the first hospitalization for ALI,

- Patients with previous hospital stay for chronic liver disease (alcoholic cirrhosis, chronic hepatitis, alcoholics or malignant neoplasm (pancreatic or hepatobiliary)), 
- Patients with a medical procedure including endoscopies, diagnostic procedures, or related to HIV disease during the first hospitalization for ALI,

- Patients with hospitalization (whatever the main diagnosis) ending within the previous 30 days, or starting more than 7 days before the first hospitalization for ALI, because the database does not contain information or the use of routine drugs in hospital, so that exposure in such cases could not be ascertained.

\subsection{Definition of reference populations}

The reference population was identified in the EGB database as all subjects aged 18 years and over. The total exposed population for each drug of interest was estimated from the number of patients dispensed that drug at least once during the study period. That number was extrapolated to the general population based on the age and gender structure in France at each considered year according to data published by the French national institute of statistics (Institut National de la Statistique et des Etudes Economiques, INSEE) [30].

In this situation, EGB is a convenience sample that is readily accessible, and is representative of the contents of the whole SNDS database. EGB has been used similarly for the casepopulation study of liver transplantation [2, 20, 29], for the feasibility study of EPIHAM [18], for other drug utilisation studies [31, 32], as well as for many other studies. In the present design it was clearly not feasible nor useful to ask for drug utilisation data in 66 million persons for each of the $200+$ drugs identified.

\subsection{Definition of exposure}

Drug exposures in cases were defined as at least one recorded dispensing within the 7-60 days period before the index date. The 7-day lag time was chosen to minimise protopathic (drug 
given for the symptoms of hepatic injury) and indication bias (drugs given for a disease that causes hepatic injury). The first would typically be antiemetic agents early before the onset of clinical hepatitis, the latter the use of loop diuretics in acute heart failure resulting in "cardiac liver".

Drug exposures in the reference population were defined according to two different metrics;

- As number of subjects with at least one drug dispensing during the study period, as might be recommended for idiosyncratic liver injury, which occurs in susceptible individuals early in the treatment [20] [33]

- As total number of Defined Daily Doses (DDD) dispensed over the study period. This corresponds to the more classical person-time approach [27], which would be appropriate to drugs with a direct, cumulative toxicity, but which probably overestimates risks for drugs with mostly short-term use [20].

Drugs of interest were identified by their anatomical therapeutic chemical (ATC) codes at the various levels, from drug classes (3 digit code, e.g., A02; drugs for acid related disorders), to the 4 digit chemical class, (e.g. M01A NSAIDs) to the 7-digit individual product code (eg, N02BE01 paracetamol). Classes, families and drugs of interest were identified by the frequency in the cases.

\subsection{Statistical analyses}

ALI cases were described, using standard statistical metrics for quantitative and qualitative variables. 
Event rates of ALI for each drug, family or class of interest were estimated as the total number of cases exposed to the drug within 7-60 days before ALI to the total number of patients exposed during the study period, with their 95\% Poisson confidence intervals, and to the total number of DDD dispensed over the study period with their 95\% Poisson confidence intervals

Drugs, families or classes with fewer than 5 exposed cases were not analysed.

For descriptive purposes, the instant and cumulative hazards were determined for the typical hepatotoxic drugs valproic acid and erythromycin as representative of different toxic mechanisms, using duration of exposure previous to index date for cases, and distribution of exposure durations from the reference population. Cumulative incidences were assessed using the Kaplan-Meier method.

All Statistical analyses were carried out using SAS software versus 9.1 (SAS Institute, Cary, $\mathrm{NC})$.

\subsection{Regulatory aspects}

In accordance with the French regulations, this study received authorization from the Institute of Health Data (Institut des Données de Santé) and from the French data protection commission (Commission Nationale de l'Informatique et des Libertés). This study was registered with ENCEPP (www.encepp.eu), at the European Medicines Agency (EMA, London, UK) with the registration number ENCEPP/SDPP/7549.

This study was supported by a grant from the French national Research Institute in Public Health ((IRESP), Grants \# AAP-2014-05 and AAP-2014-06) 


\section{Results}

\subsection{Characteristics of the cases}

Over the study timeframe, 4,807 adult cases of hospitalized ALI were identified (Figure 1), $61.4 \%$ with acute toxic liver injury and 38.6\% with hepatic failure (K72.0). More than half of the cases were women (58.7\%). The mean age was 54.5 years $(\mathrm{SD} \pm 19.8)$, compared to an average age of the French population of 40.4 years. Among these cases, $47.8 \%$ had at least one registered chronic disease. The most common $(\geq 5 \%)$ were diabetes $(10.6 \%)$, chronic psychiatric disorders $(9.1 \%)$, and malignant tumours, malignant lymphatic or hematopoietic tissue diseases (6.7\%). Nearly all cases $(97.6 \%)$ had at least one consultation or medical visit within 12 months before the index date, and most of them had seen their general practitioner (83.4\%). The average number of medical visits within 12 months before the index date was $11.9(\mathrm{SD} \pm 10.8)$, the mean duration of ALI hospitalization was 6.9 days $(\mathrm{SD} \pm 7.1)$ and $79.8 \%$ of the cases had one or more associated diagnoses at index date (Table 1).

\subsection{Exposures}

There were 249 different drugs of interest with at least one dispensing within 7-60 days before index date in 3,633 ALI cases (75.6\%), with at least 5 cases exposed per drug (Figure 2). The most frequent ATC classes or families were analgesics (N02, 40.6\%), drugs for acid related disorders (A02, 31.6\%), anxiolytics or hypnotics (at least one N05B or N05C, 23.6\%), antibacterials for systemic use (J01, 23.1\%), agents acting on the renin-angiotensin system $(\mathrm{C} 09,20.0 \%)$, lipid modifying agents $(\mathrm{C} 10,18.7 \%)$, antithrombotic agents (B01, 18.2\%), NSAIDs (M01A, 17.0\%), psychoanaleptics (N06, 16.6\%) and drugs for functional gastrointestinal disorders (A03, 15.3\%). 
The drugs (ATC with 7 digit code) most frequently dispensed within 7-60 days period before ALI were paracetamol with 1,495 cases $(31.1 \%$ of all cases), esomeprazole (10.4\%), omeprazole (8.5\%), phloroglucinol (6.5\%), domperidone $(6.2 \%)$, amoxicillin in combination with enzyme inhibitors $(6.1 \%)$, furosemide $(5.9 \%)$, atorvastatin $(5.5 \%)$, pantoprazole $(5.1 \%)$ and zolpidem (5.1\%) (Table 2).

Some drugs were those widely dispensed both in cases and in the general population such as furosemide (284 cases), atorvastatin (263 cases) and bisoprolol (210 cases), with relatively high event rates around one case for 15,000 exposed patients.

\subsection{Drugs with highest event rates per patient}

The drugs with the highest event rates (exposed cases per exposed population) of ALI were antimycobacterials (J04). The combination of rifampicin, pyrazinamide and isoniazid was the highest ranked drug with one hospital admission for ALI in 578 exposed patients, followed by pyrazinamide alone (one case for 770 exposed patients), ethambutol (one case for 825 exposed patients), isoniazid (one case for 1,281 exposed patients) and rifampicin-isoniazid combination (one case for 1,928 exposed patients) (Table 3). The 25 highest ranked drugs also included colestyramine (one case of ALI for 5,312 exposed patients), erythromycin (one case for 5,374 exposed patients), cibenzoline (one case for 6,452 exposed patients) or methyldopa (one case for 6,719 exposed patients). Among these drugs one also finds antiepileptics (oxcarbazepine, phenobarbital, carbamazepine, valproic acid, and lamotrigine) with 1 case for 8 to 10000 patients treated; anti-Alzheimer drugs rivastigmine, memantine, galantamine with $1 / 11000$ to $1 / 12000$ patients, and anticoagulants acenocoumarol and warfarin (around 1/11000 patients), and a number of drugs used to treat heart failure, such as 
isosorbide mononitrate, carvedilol, betaxolol, captopril, which could suggest miscoding of heart-failure associated hepatic injury, or heart failure as a risk factor for drug-related ALI. These top 25 drugs were among the drugs with the lowest numbers of exposed cases, 71 or fewer.

\subsection{Drugs with the highest event rate per patient-time}

A common measure of exposure is patient-time rather than patients as presented in table 4 . The drugs with the highest rate of ALI per DDD are the same as those per patient, i.e. antituberculosis drugs. 21 out of the 25 drugs with high per-DDD event rate were antibacterial agents, with event rates below 1 case per million DDD. These are drugs with short treatment duration: in this case the number of patients per DDD is highest, which could explain such high per DDD risk if the event is not dose/duration dependent but patient dependent (idiosyncratic) [20].

\section{6: Hazard functions}

Comparing drug utilisation patterns in cases and the general user population may give indications on hazard functions and possible mechanisms of drug toxicity. As examples, we chose to consider erythromycin and valproic acid: the former is a typical type B (idiosyncratic) reaction, with a risk that is maximal at 10 days of treatment, and decreases thereafter (Figure 3). The initial zero-risk period between the date of dispensing and the index date for ALI is related to the 7-day exclusion period: none of the dispensings during these 7 days are considered (zero-exposure bias, akin to immortal time bias).

During valproic acid exposure, on the other hand, the risk of ALI was constant over time, so that the cumulative risk increases with duration of exposure (Figure 4). 


\section{Discussion}

\subsection{Main results}

This population-based study provides a countrywide assessment of patients admitted for toxic acute liver injury, and the drugs dispensed during a period that would provide exposure that is compatible with a causality of the drug in the event (RUCAM) [34, 35]. In this initial report we describe individual drugs most concerned and a general overview of the possible use of such an approach for alert generation purposes, including the overall population burden of ALI for individual drugs by the absolute number of cases that were exposed to the drug of interest, and for the individual risk by the number of patients dispensed the drug for each case of ALI.

The diagnostic criteria we chose for ALI were rather restrictive: all cases with indications of a possible other cause were excluded, based on main, associated or secondary hospitalisation diagnosis or chronic disease ICD10 codes indicative of for instance alcoholic liver disease, other toxins, viral diseases or other clinically defined causes for liver injury. For legal privacy reasons we are not allowed to return from the recorded diagnoses to the individual patient files so that we have to rely on the quality of hospital diagnoses and coding.

Though errors may of course be possible and certainly occurred, it may be thought unlikely that they would be affected by drug exposure, though certainly exposure to known hepatotoxic drugs may have resulted in wrongly attributing the ALI to the exposure rather than to another cause, for instance viral. This is unlikely: viral tests are systematic at admission for ALI. On the other hand, drugs not thought to be associated with ALI, and that may not be cited in clinical files or spontaneous reports, will be identified from dispensing data. 
Drugs whose first dispensing was within 0-7 days before the date of hospital admission were excluded. Hepatic lab tests before index date were done within 7 days before hospital admission, which could indicate that the hepatic symptoms started before that date. Drugs with a first dispensing after that day could have been prescribed because of ALI symptoms (protopathic bias). Indeed, drugs most often first dispensed within 7 days before index date were symptomatic medications (analgesics, antiemetics, propulsives) that could be related to the symptoms of hepatic injury (abdominal pain, nausea or vomiting, dyspepsia). This does not formally exclude that they may have been involved in the occurrence of ALI, but the chance of bias is such that we preferred to exclude them in a first analysis. This does not concern drugs that may have been renewed within the 0-7 days timeframe, but had already been prescribed before.

Our results are generally consistent with expectations $[16,36]$ : the drug most commonly dispensed between 7 and 60 days before admission for ALI was paracetamol with 1,495 cases, the drug by far the most dispensed in France [31]. Paracetamol was present in more than $30 \%$ of all ALI cases, with one case per 35,000 persons dispensed paracetamol at least once in 5 years. Other drugs often found before ALI were the proton pump inhibitor omeprazole (or esomeprazole, its active isomer), for 910 cases altogether (19\%) and one case per 35000 users of either. Phloroglucinol, and domperidone are drugs used for symptoms of the digestive sphere that may be associated with ALI, and for which further analyses will be needed to elucidate the exact chronology and likelihood of protopathic bias, also called reverse causality, a drug being prescribed for the event studied rather than causing it. Further down the list, drugs are found that are known to cause known liver injury and probably escape protopathic bias such as amoxicillin+clavulanic acid, furosemide or atorvastatin. Of course the absolute number of cases is not indicative of increased hepatotoxic risk per se, just that the 
drugs may be widely used. These drugs are among the most frequently used, such as paracetamol (52 million exposed adult patients over 5 years, i.e., most adult population), coamoxiclav (19 million users), ibuprofen (26 million users), desloratadine (13 million users) or ketoprofen (19 million users). They did not head the ranking for event rates, with fewer than 7 cases per 100,000 exposed patients, or 1 case for 14,000 exposed patients. The large numbers of hepatic events may however impact overall medical resource utilisation and should be considered in the overall risk-benefit ratio of similar drugs.

To have an indication of the actual risk with individual drugs, one needs to turn to per-user event rates. Of course this is only indicative, and any attempt to compare drugs should be extremely cautious, using the appropriate adjustment methods and a good knowledge of the disease states the drugs are prescribed in. Different drugs are prescribed to different patients with different susceptibilities to liver injury related to patient backgrounds and to the diseases treated. However, within drug families, which share common indications and are used in similar patients, there may be no major differences in the patients or only few confounders. Different event rates may raise signals of possible concern, and may lead to further explorations. For instance, the first drugs for events per patient are the antimycobacterial drugs, where ALI occurs in one out of 600 to 2,000 exposed patients. Antimycobacterial drugs are known to be hepatotoxic. Rifampicin alone may be less toxic than the others. The next drug by importance of risk is colestyramine, one in 5000 users. Of course colestyramine is given for pruritus in chronic jaundice, which might also suggest protopathic bias or at least a risk factor for acute injury. This will certainly warrant further exploration to test what other drugs may have been associated with colestyramine in these cases. It has been reported as an antidote to paracetamol, $[37,38]$ and is used to facilitate the elimination of toxins. However increased transaminases have also been reported, but without overt liver injury. [39] 
Among the well-known hepatotoxic agents one finds methyldopa $(1 / 6,700)$, the antiepileptic drugs carbamazepine, oxcarbazepine, phenobarbital, valproic acid, and lamotrigine, all with around one case in 7-9 000 patients. Drugs used in heart failure (isosorbide mononitrate, carvedilol, or betaxolol) with 1/10-11,000 patients suggest potential confounding by indication, and the possibility of misdiagnosed heart failure and cardiac liver disease. Warfarine and acenocoumarol have the same event rate $(1 / 11,400)$, but fluindione and the direct acting anticoagulants do not appear in this list. The anti-Alzheimer drugs memantine, rivastigmine, galantamine also appear together with around one case in 12000 exposed patients, a toxicity also previously described with tacrine [40].

Erythromycine, with one case in 5,400 patients, is the only macrolide in this list. The first descriptions of erythromycin hepatotoxicity date back to the early 1960's [41]. Hepatotoxicity seems to have been associated with all its esters or salts [42]. There have been recent metaanalyses of the hepatic risks of antibiotics or macrolides within the European IMI-Protect project, but not comparing the individual drugs $[43,44]$. Further analyses will be needed to verify whether the apparent risk we found is related to uses of erythromycin in patients at high risk of ALI, or whether it is a specific risk of the drug, different from the other macrolides, in which case the real benefits of this ancient drug might need to be reconsidered.

\subsection{Strengths}

The main strength of our study is its power: studying 5 years of hospital admissions for ALI in a whole country database yields a much greater number of cases than previous studies, enabling the study of over 200 different drugs.

The study population was exhaustive and representative of the French population, through data sources that cover nearly all the country's population. Because this database was not set 
up for this study, neither selection bias nor recall bias should be an issue. The case-population design has been proven feasible, adequate, and efficient by the SALT study, even on a wider scale, for ALFT, a very rare event with $100 \%$ ascertainment rates [2, 3, 20]. Selection bias was also reduced by the choice of inclusion and exclusion criteria that provided an accurate definition of acute hepatotoxicity from medicines. The defined exposure period reduced protopathic bias, as drugs dispensed in the 7 days before hospital admission for ALI could have been prescribed to relieve the symptoms of liver failure.

Since the drug utilisation patterns can be described in cases and the reference populations, it is feasible to compare the drug dispensing patterns in cases compared to the general population and derive hazard function curves.

\subsection{Limitations}

As all claims and hospital admissions databases, there are limitations.

The first concerns the diagnosis of acute liver injury. Because we cannot identify patients from the database, we cannot directly validate the diagnoses, and have to rely on hospital coder proficiency and professionalism. The basic coding is generated by hospital personnel, usually for statistical and billing purposes. In recent years, professional coders have been deployed in some hospitals, mostly to ensure the quality and consistency of coding and the proper coding of associated diagnoses. There are national coding instructions for various diseases, to ensure homogeneous coding over the thousands of hospitals concerned.

The algorithms we used excluded other causes of acute liver injury, such as viral diseases, non-drug toxicity (chemical, plants), cardiac disorders, Budd-chiari syndrome and other vascular diseases, as well as acute drug intoxications, especially paracetamol. In addition to the codes used for the main diagnosis, other information such as secondary codes, or 
indication of chronic disease or alcohol related disorders were used to exclude cases. Hospital stays for whatever reason within the 7-60 days before ALI were also a reason for exclusion, since during the hospital period there is no indication on drug exposures, so that potential exposures of interest could be missed.

Exposure was measured by drug dispensing, which is one step closer to actual exposure than prescriptions or electronic health records. Ideally one would want to have direct contact with the patient, knowing that even that is sometimes uncertain $[45,46]$. Though most claims databases cannot identify OTC drugs, in France over $84 \%$ of the paracetamol and $70 \%$ of analgesic strength ibuprofen is prescribed and identified in the database $[31,32,47]$. Drug dispensing is specific and precise, in that only commercial preparations are dispensed, indicating the exact number of tablets, and their individual strength, so that the total quantity of drug that is dispensed in known.

Further analyses will consider individual drug classes (e.g., NSAIDs, antidepressants, antiepileptic drugs or antibiotics, as well as different analytical strategies, beyond the casepopulation approach used here, such as case-control, case crossover or self-controlled case series. These will be used to compare event rates or odds ratios of different drugs within the same indications or drug families.

\subsection{Future developments}

Such a resource may be used to test known hepatotoxic drugs, compare marketed drugs within drug families, and confirm the validity of the method. A potential use could also be for early recognition of drug alerts of hepatotoxicity, once the background rates of hepatotoxicity have been established for drug classes or clinical situations. We voluntarily restricted the analysis to only the drugs with at least 5 cases exposed over 5 years. This would be too 
restrictive for alert generation where even one case for instance in the first years of marketing may be of interest. Early surveillance of new cases in the SNDS exposed to newly marketed drugs, may alert to the hepatotoxic potential of such new drugs. The main restriction is the data delay: the hospital data (cases) are available for a given year in the third quarter of the following year year. This may be enough for routine surveillance of new drugs, may too long for emerging acute drug alerts, and needs to be compared to the performance of the spontaneous reporting system.

\section{Conclusion}

To conclude, this first analysis of the collection of all toxic ALI admitted to hospital in France over 5 years already provides information on the drugs associated with the greatest burden of ALI, and drugs with the highest apparent individual risk. Paracetamol is by far the drug most often associated with hospitalisation for ALI, but it is also by far the drug most often prescribed in France, at least once in 5 years to $80 \%$ of the population. At the other end of the spectrum, antituberculosis antibiotics were by far the most hepatotoxic drugs, with the highest individual risk of hepatotoxicity, whether per patient or per DDD.

This study provides a rich source of information on suspected hepatotoxicity, which will be explored using different analytical methods. Individual drugs and drugs families will be further explored, as will be the use of this method to generate alerts. Interested researchers are invited to contribute and participate in this research. 


\section{Acknowledgements}

The authors wish to thank ADERA, the non-profit organization that provides legal, administrative and human resources support to Bordeaux PharmacoEpi;

\section{Compliance with ethical standards.}

The corresponding author has full access to all of the data in the study, and takes responsibility for the integrity of the data and accuracy of the data analysis.

\subsection{Conflicts of interest}

Nicholas Moore, Stephanie Duret, Adeline Grolleau, Regis Lassalle, Vanessa Barbet, Mai Duong, Nicolas Thurin, Cécile Droz-Perroteau, Sinem Ezgi Gulmez have no conflicts of interest that are directly relevant to the content of this study

All authors have completed the Unified Competing Interest form at

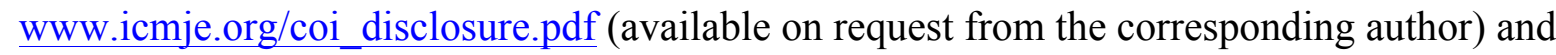
declare: no support from any organisation for the submitted work, no other relationships or activities that could appear to have influenced the submitted work. Bordeaux PharmacoEpi receives funding from various pharmaceutical companies and governmental bodies to conduct research on marketed drugs at the request of regulatory authorities, or as a consequence of research grant applications. None of these concern the subject at hand.

\subsection{Funding}

This study was supported by an unconditional public joint grant from Direction Générale de la Santé (DGS), from Mission recherche de la Direction de la recherche, des etudes, de 
l'évaluation et des statistiques (MiRe-DREES) of Caisse Nationale d'Assurance Maladie des Travailleurs Salariés (CNAMTS), Régime Social Indépendants (RSI) and Caisse Nationale de Solidarité pour l'Autonomie (CNSA), as part of the general call for projects by IReSP (Appel à Projets, Institut de Recherche en Santé Publique), n² 2013-29. It was designed, conducted and analysed independently by the Bordeaux PharmacoEpi Research Platform, CIC Bordeaux CIC1401.

\subsection{Ethical approval.}

In accordance with the French regulations, this study received authorization from the Institute of Health Data (Institut des Données de Santé) and from the French Data Protection Agency (Commission Nationale de l'Informatique et des Libertés). This study was registered with ENCEPP (www.encepp.eu), at the European Medicines Agency (EMA, London, UK) with the registration number ENCEPP/SDPP/7549.

\subsection{Patient consent}

Not applicable. 


\section{References}

1. Gulmez SE, Larrey D, Pageaux GP, Bernuau J, Bissoli F, Horsmans Y, et al. Liver transplant associated with paracetamol overdose: results from the seven-country SALT study. Br J Clin Pharmacol. 2015 Sep;80(3):599-606.

2. Gulmez SE, Larrey D, Pageaux GP, Lignot S, Lassalle R, Jove J, et al. Transplantation for acute liver failure in patients exposed to NSAIDs or paracetamol (acetaminophen): the multinational casepopulation SALT study. Drug Saf. 2013 Feb;36(2):135-44.

3. Gulmez SE, Larrey D, Pageaux GP, Lignot-Maleyran S, de Vries C, Sturkenboom M, et al. Methodology for a multinational case-population study on liver toxicity risks with NSAIDs: the Study of Acute Liver Transplant (SALT). Eur J Clin Pharmacol. 2013 Mar;69(3):605-16.

4. Keisu M, Andersson TB. Drug-induced liver injury in humans: the case of ximelagatran. Handb Exp Pharmacol. 2010(196):407-18.

5. Reuben A, Koch DG, Lee WM, Acute Liver Failure Study G. Drug-induced acute liver failure: results of a U.S. multicenter, prospective study. Hepatology. 2010 Dec;52(6):2065-76.

6. Lee WM. Drug-induced hepatotoxicity. N Engl J Med. 2003 Jul 31;349(5):474-85.

7. Bernal W, Auzinger G, Dhawan A, Wendon J. Acute liver failure. Lancet. 2010 Jul 17;376(9736):190-201.

8. Zimmerman HJ. Hepatotoxicity:The Adverse Effects of Drugs and Other Chemicals on the Liver. 2nd ed. Philadelphia, PA, USA.: Lippincott Williams \& Wilkins; 1999.

9. David S, Hamilton JP. Drug-induced Liver Injury. US Gastroenterol Hepatol Rev. 2010 Jan 1;6:73-80.

10. Navarro VJ, Senior JR. Drug-related hepatotoxicity. N Engl J Med. 2006 Feb 16;354(7):731-9.

11. Zimmerman HJ. The spectrum of hepatotoxicity. Perspect Biol Med. 1968 Autumn;12(1):135-

61.

12. Zimmerman HJ. Drug-induced liver disease. Drugs. 1978 Jul;16(1):25-45.

13. Gulmez SE, Lignot-Maleyran S, de Vries CS, Sturkenboom M, Micon S, Hamoud F, et al. Administrative complexities for a European observational study despite directives harmonising requirements. Pharmacoepidemiol Drug Saf. 2012 Aug;21(8):851-6.

14. Donati M, Conforti A, Lenti MC, Capuano A, Bortolami O, Motola D, et al. Risk of acute and serious liver injury associated to nimesulide and other NSAIDs: data from drug-induced liver injury case-control study in Italy. Br J Clin Pharmacol. 2016 Jul;82(1):238-48.

15. Douros A, Bronder E, Andersohn F, Klimpel A, Thomae M, Sarganas G, et al. Drug-induced liver injury: results from the hospital-based Berlin Case-Control Surveillance Study. Br J Clin Pharmacol. 2015 Jun;79(6):988-99.

16. Sabate M, Ibanez L, Perez E, Vidal X, Buti M, Xiol X, et al. Risk of acute liver injury associated with the use of drugs: a multicentre population survey. Aliment Pharmacol Ther. 2007 Jun 15;25(12):1401-9.

17. Sobhonslidsuk A, Poovorawan K, Soonthornworasiri N, Pan-Ngum W, Phaosawasdi K. The incidence, presentation, outcomes, risk of mortality and economic data of drug-induced liver injury from a national database in Thailand: a population-base study. BMC Gastroenterol. 2016 Oct 28;16(1):135.

18. Gulmez SE, Unal US, Lassalle R, Chartier A, Grolleau A, Moore N. Risk of hospital admission for liver injury in users of NSAIDs and nonoverdose paracetamol: Preliminary results from the EPIHAM study. Pharmacoepidemiol Drug Saf. 2018 Aug 16.

19. Bezin J, Duong M, Lassalle R, Droz C, Pariente A, Blin P, et al. The national healthcare system claims databases in France, SNIIRAM and EGB: Powerful tools for pharmacoepidemiology.

Pharmacoepidemiol Drug Saf. 2017 Aug;26(8):954-62.

20. Moore N, Gulmez SE, Larrey D, Pageaux GP, Lignot S, Lassalle R, et al. Choice of the denominator in case population studies: event rates for registration for liver transplantation after exposure to NSAIDs in the SALT study in France. Pharmacoepidemiol Drug Saf. 2013 Feb;22(2):160-7. 
21. Bezin J, Girodet PO, Rambelomanana S, Touya M, Ferreira P, Gilleron V, et al. Choice of ICD10 codes for the identification of acute coronary syndrome in the French hospitalization database. Fundamental \& clinical pharmacology. 2015 Dec;29(6):586-91.

22. Gilleron V, Gasnier-Duparc N, Hebbrecht G. Certification des comptes: Une incitation à la traçabilité des processus de contrôle. Revue Hospitaliere de France. 2018;582:42-6.

23. Aladjidi N, Jutand MA, Beaubois C, Fernandes H, Jeanpetit J, Coureau G, et al. Reliable assessment of the incidence of childhood autoimmune hemolytic anemia. Pediatr Blood Cancer. 2017 Dec;64(12).

24. Bosco-Lévy P, Duret S, Picard F, Dos Santos P, Puymirat E, Gilleron V, et al. Diagnostic accuracy of the international classification of disease 10th revision codes of heart failure in administrative database Pharmacoepidemiol Drug Saf. 2018;27:in press.

25. Daveluy A, Miremont-Salame G, Kostrzewa A, Couret A, Lacoin L, Lecomte C, et al. Identification of abuse and dependence cases through a hospital database. Pharmacoepidemiol Drug Saf. 2012 Dec;21(12):1344-9.

26. Gouverneur A, Dolatkhani D, Rouyer M, Grelaud A, Francis F, Gilleron V, et al. Agreement between hospital discharge diagnosis codes and medical records to identify metastatic colorectal cancer and associated comorbidities in elderly patients. Rev Epidemiol Sante Publique. 2017 Aug;65(4):321-5.

27. Theophile H, Laporte JR, Moore N, Martin KL, Begaud B. The case-population study design: an analysis of its application in pharmacovigilance. Drug Saf. 2011 Oct 01;34(10):861-8.

28. Capella D, Pedros C, Vidal X, Laporte JR. Case-population studies in pharmacoepidemiology. Drug Saf. 2002;25(1):7-19.

29. Moore N, Gulmez SE, Blin P, Lassalle R, Jove J, Theophile H, et al. Relative risks from casepopulation data. Epidemiology. $2013 \mathrm{Nov}$;24(6):935-6.

30. Institut national de la statistique et des études économiques. Pyramides des âges (Population totale par sexe et âge - France et France métropolitaine). [cited; Available from:

http://www.insee.fr/fr/themes/detail.asp?reg_id=0\&ref_id=bilan-demo

31. Duong M, Gulmez SE, Salvo F, Abouelfath A, Lassalle R, Droz C, et al. Usage patterns of paracetamol in France. Br J Clin Pharmacol. 2016 Aug;82(2):498-503.

32. Duong M, Salvo F, Pariente A, Abouelfath A, Lassalle R, Droz C, et al. Usage patterns of 'overthe-counter' vs. prescription-strength nonsteroidal anti-inflammatory drugs in France. Br J Clin Pharmacol. 2014 May;77(5):887-95.

33. Moride $Y$, Abenhaim L. Evidence of the depletion of susceptibles effect in non-experimental pharmacoepidemiologic research. J Clin Epidemiol. 1994 Jul;47(7):731-7.

34. Benichou C, Danan G, Flahault A. Causality assessment of adverse reactions to drugs--II. An original model for validation of drug causality assessment methods: case reports with positive rechallenge. J Clin Epidemiol. 1993 Nov;46(11):1331-6.

35. Danan G, Benichou C. Causality assessment of adverse reactions to drugs--I. A novel method based on the conclusions of international consensus meetings: application to drug-induced liver injuries. J Clin Epidemiol. 1993 Nov;46(11):1323-30.

36. Sgro C, Clinard F, Ouazir K, Chanay H, Allard C, Guilleminet C, et al. Incidence of drug-induced hepatic injuries: a French population-based study. Hepatology. 2002 Aug;36(2):451-5.

37. Rosa H, Prudente MS, Cardoso VM. Paracetamol hepatic necrosis and its prevention by cholestyramine. Arq Gastroenterol. 1984 Oct-Dec;21(4):164-6.

38. Siegers CP, Moller-Hartmann W. Cholestyramine as an antidote against paracetamol-induced hepato- and nephrotoxicity in the rat. Toxicol Lett. 1989 May;47(2):179-84.

39. Singhal R, Harrill AH, Menguy-Vacheron F, Jayyosi Z, Benzerdjeb H, Watkins PB. Benign elevations in serum aminotransferases and biomarkers of hepatotoxicity in healthy volunteers treated with cholestyramine. BMC Pharmacol Toxicol. 2014 Aug 3;15:42.

40. Watkins PB, Zimmerman HJ, Knapp MJ, Gracon SI, Lewis KW. Hepatotoxic effects of tacrine administration in patients with Alzheimer's disease. JAMA. 1994 Apr 6;271(13):992-8.

41. Johnson DF, Jr., Hall WH. Allergic hepatitis caused by propionyl erythromycin ester of lauryl sulfate. N Engl J Med. 1961 Dec 14;265:1200-2. 
42. Pessayre D, Benhamou JP. Hepatotoxicity of erythromycin derivatives. Br Med J. 1979 May 19;1(6174):1357.

43. Brauer R, Douglas I, Garcia Rodriguez LA, Downey G, Huerta C, de Abajo F, et al. Risk of acute liver injury associated with use of antibiotics. Comparative cohort and nested case-control studies using two primary care databases in Europe. Pharmacoepidemiol Drug Saf. 2016 Mar;25 Suppl 1:2938.

44. Ferrer $\mathrm{P}$, Amelio J, Ballarin $\mathrm{E}$, Sabate $\mathrm{M}$, Vidal $\mathrm{X}$, Rottenkolber $\mathrm{M}$, et al. Systematic Review and Meta-Analysis: Macrolides- and Amoxicillin/Clavulanate-induced Acute Liver Injury. Basic Clin Pharmacol Toxicol. 2016 Jul;119(1):3-9.

45. Moore $\mathrm{N}$, Masson $\mathrm{H}$, Noblet $\mathrm{C}$, Joannidès R. What medicines do patients really take? A comparison of free form vs oriented questionnaires. Post Marketing Surveillance. 1993;7:355-62. 46. Moore N, Pierfitte C, Pehourcq F, Lagnaoui R, Begaud B. Comparison of patient questionnaires, medical records, and plasma assays in assessing exposure to benzodiazepines in elderly subjects. Clin Pharmacol Ther. 2001;69(6):445-50.

47. Duong M, Abouelfath A, Lassalle R, Droz C, Blin P, Moore N. Coronary Events After Dispensing of Ibuprofen: A Propensity Score-Matched Cohort Study Versus Paracetamol in the French Nationwide Claims Database Sample. Drug Saf. 2018 May 24. 
Table 1. Characteristics of cases of hospital admissions for acute liver injury cases identified in the French national health data SNDS from 2010 to 2014

\begin{tabular}{|c|c|}
\hline & Cases \\
\hline & $\mathrm{n}=4,807$ \\
\hline Gender - Female, n (\%) & $2,822(58.7)$ \\
\hline Age at index date (in years), mean $( \pm \mathrm{SD})$ & $54.5(19.8)$ \\
\hline At least one LTD declared before ID, n (\%) & $2,298(47.8)$ \\
\hline LTD “Diabetes type 1, diabetes type 2", n (\%) & $510(10.6)$ \\
\hline LTD “Long-term psychiatric conditions”, n (\%) & $439(9.1)$ \\
\hline LTD "Malignant tumours, malignant lymphatic or hematopoietic tissue, n (\%) & $324(6.7)$ \\
\hline At least one transaminase test within 7 days before ID, n (\%) & $205(4.3)$ \\
\hline At least one medical visit during the 12 months before ID, $\mathrm{n}(\%)$ & $4,691(97.6)$ \\
\hline General practitioner, $\mathrm{n}(\%)$ & $4,008(83.4)$ \\
\hline Ophthalmology, n (\%) & $948(19.7)$ \\
\hline Hospital practitioner (Unknown specialty), n (\%) & $817(17.0)$ \\
\hline Gastroenterology and hepatology, n (\%) & $667(13.9)$ \\
\hline Dermatology, n (\%) & $591(12.3)$ \\
\hline Cardiology, n (\%) & $580(12.1)$ \\
\hline Anaesthetics, n (\%) & $552(11.5)$ \\
\hline
\end{tabular}

Number of medical visits per patient during the 12 months before ID, mean $( \pm \mathrm{SD})$

$11.9(10.8)$

ICD-10 code diagnosis of hospitalization for ALI

K71.1 - toxic liver disease with hepatic necrosis, n (\%)

K71.2 - toxic liver disease with acute hepatitis, $\mathrm{n}(\%)$

K71.6 - toxic liver disease with hepatitis, not elsewhere described, n (\%)

$673(14.0)$

K71.9 - toxic liver disease, unspecified. n (\%)

K72.0 - acute and subacute liver failure, n (\%)

1,857 (38.6) 


\begin{tabular}{|c|c|}
\hline & Cases \\
\hline & $\mathrm{n}=4,807$ \\
\hline Duration of hospitalization for ALI (in days), mean $( \pm \mathrm{SD})$ & $6.9(7.1)$ \\
\hline \multicolumn{2}{|l|}{ Number of associated diagnoses per patient at ID, n (\%) } \\
\hline 0 & $971(20.2)$ \\
\hline 1 to 4 & $2,665(55.4)$ \\
\hline 5 to 8 & $816(17.0)$ \\
\hline$>8$ & $355(7.4)$ \\
\hline \multicolumn{2}{|l|}{$\begin{array}{l}\text { ICD- } 10 \text { code of associated diagnoses at ID (several diseases possible - ICD-10 } \\
\text { main chapters) }\end{array}$} \\
\hline $\begin{array}{l}\text { Symptoms, signs and abnormal clinical and laboratory findings, not elsewhere } \\
\text { classified, } \mathrm{n}(\%)\end{array}$ & $1,617(33.6)$ \\
\hline Endocrine, nutritional and metabolic diseases, $\mathrm{n}(\%)$ & $1,382(28.7)$ \\
\hline Diseases of the circulatory system, $\mathrm{n}(\%)$ & $1,117(23.2)$ \\
\hline External causes of morbidity and mortality, $\mathrm{n}(\%)$ & $962(20.0)$ \\
\hline Diseases of the digestive system, $\mathrm{n}(\%)$ & $888(18.5)$ \\
\hline Factors influencing health status and contact with health services, $\mathrm{n}(\%)$ & $821(17.1)$ \\
\hline Mental and behavioural disorders, $\mathrm{n}(\%)$ & $661(13.8)$ \\
\hline Certain infectious and parasitic diseases, $\mathrm{n}(\%)$ & $584(12.1)$ \\
\hline Diseases of the genito-urinary system, $\mathrm{n}(\%)$ & $551(11.5)$ \\
\hline
\end{tabular}

SNDS, Système National des Données de Santé; SD, Standard deviation; LTD, Long-Term disease; ID, Index Date; ICD, International Classification of Diseases ; ALI, Acute Liver Injury 
Table 2. Top 25 drugs dispensed within 7-60 days before hospital admission for ALI between 2010 and 2014, by number of exposed ALI.

\begin{tabular}{|c|c|c|c|c|c|c|}
\hline & $\begin{array}{c}\text { Number of ALI } \\
n(\%) \\
n=4,807 \\
\end{array}$ & $\begin{array}{c}\text { Number of DDD } \\
\text { dispensed } \\
\mathrm{n}=119,310,075,800\end{array}$ & $\begin{array}{c}\text { Number of users } \\
\text { over } 5 \text { years } \\
n=65,375,384\end{array}$ & $\begin{array}{c}\text { Number of cases per } \\
\text { million DDD } \\
{[95 \% \mathrm{CI}]}\end{array}$ & $\begin{array}{c}\text { Number of cases per } \\
10000 \text { users } \\
{[95 \% \mathrm{CI}]}\end{array}$ & $\begin{array}{l}\text { Number of } \\
\text { users/ case }\end{array}$ \\
\hline N02BE01 - Paracetamol & $1,495(31.1)$ & $5,219,032,555$ & $52,020,957$ & $0.29[0.26 ; 0.32]$ & $0.29[0.26 ; 0.32]$ & 34,797 \\
\hline A02BC05 - Esomeprazole & $502(10.4)$ & $2,982,803,352$ & $14,161,092$ & $0.17[0.15 ; 0.19]$ & $0.35[0.31 ; 0.40]$ & 28,209 \\
\hline A02BC01 - Omeprazole & $408(8.5)$ & $2,260,375,155$ & $17,494,549$ & $0.18[0.16 ; 0.20]$ & $0.23[0.21 ; 0.26]$ & 42,879 \\
\hline A03AX12 - Phloroglucinol & $311(6.5)$ & $568,912,425$ & $20,033,756$ & $0.55[0.48 ; 0.62]$ & $0.16[0.14 ; 0.18]$ & 64,417 \\
\hline A03FA03 - Domperidone & $298(6.2)$ & $850,851,417$ & $13,555,192$ & $0.35[0.31 ; 0.40]$ & $0.22[0.19 ; 0.25]$ & 45,487 \\
\hline $\begin{array}{l}\text { J01CR02 - Amoxicillin and enzyme } \\
\text { inhibitor }\end{array}$ & $293(6.1)$ & $724,464,594$ & $19,059,269$ & $0.40[0.35 ; 0.46]$ & $0.15[0.13 ; 0.18]$ & 65,049 \\
\hline C03CA01 - Furosemide & $284(5.9)$ & $3,432,035,850$ & $4,284,346$ & $0.08[0.07 ; 0.09]$ & $0.66[0.58 ; 0.76]$ & 15,086 \\
\hline C10AA05 - Atorvastatin & $263(5.5)$ & $3,839,738,298$ & $4,140,201$ & $0.07[0.06 ; 0.08]$ & $0.64[0.55 ; 0.73]$ & 15,742 \\
\hline A02BC02 - Pantoprazole & $245(5.1)$ & $1,130,527,478$ & $8,622,136$ & $0.22[0.19 ; 0.25]$ & $0.28[0.25 ; 0.33]$ & 35,192 \\
\hline N05CF02 - Zolpidem & $244(5.1)$ & $1,623,764,111$ & $6,741,764$ & $0.15[0.13 ; 0.17]$ & $0.36[0.31 ; 0.42]$ & 27,630 \\
\hline N02AA59 - Codeine combinations & $236(4.9)$ & $480,605,654$ & $15,435,944$ & $0.49[0.42 ; 0.56]$ & $0.15[0.13 ; 0.18]$ & 65,407 \\
\hline M01AE01 - Ibuprofen & $228(4.7)$ & $658,447,116$ & $25,768,233$ & $0.35[0.30 ; 0.40]$ & $0.09[0.08 ; 0.10]$ & 113,019 \\
\hline J01CA04 - Amoxicillin & $223(4.6)$ & $924,921,578$ & $27,387,752$ & $0.24[0.21 ; 0.28]$ & $0.08[0.07 ; 0.09]$ & 122,815 \\
\hline N02AX52 - Tramadol, combinations & $217(4.5)$ & $476,468,850$ & $14,487,560$ & $0.46[0.39 ; 0.53]$ & $0.15[0.13 ; 0.17]$ & 66,763 \\
\hline N05BA12 - Alprazolam & $215(4.5)$ & $1,054,354,871$ & $7,742,811$ & $0.20[0.18 ; 0.24]$ & $0.28[0.24 ; 0.32]$ & 36,013 \\
\hline C07AB07 - Bisoprolol & $210(4.4)$ & $1,483,228,124$ & $2,977,061$ & $0.14[0.12 ; 0.16]$ & $0.71[0.61 ; 0.82]$ & 14,176 \\
\hline N05BA08 - Bromazepam & $189(3.9)$ & $1,092,243,431$ & $6,312,999$ & $0.17[0.15 ; 0.20]$ & $0.30[0.26 ; 0.35]$ & 33,402 \\
\hline C10AA07 - Rosuvastatin & $182(3.8)$ & $2,294,431,995$ & $3,705,341$ & $0.08[0.07 ; 0.09]$ & $0.49[0.42 ; 0.57]$ & 20,359 \\
\hline R06AX27 - Desloratadine & $182(3.8)$ & $1,354,186,403$ & $12,676,021$ & $0.13[0.11 ; 0.16]$ & $0.14[0.12 ; 0.17]$ & 69,648 \\
\hline N05BB01 - Hydroxyzine & $166(3.5)$ & $458,934,834$ & $6,194,431$ & $0.36[0.31 ; 0.42]$ & $0.27[0.23 ; 0.31]$ & 37,316 \\
\hline N05CF01 - Zopiclone & $163(3.4)$ & $1,110,657,434$ & $4,717,977$ & $0.15[0.12 ; 0.17]$ & $0.34[0.29 ; 0.40]$ & 28,945 \\
\hline N02AX02 - Tramadol & $162(3.4)$ & $648,184,200$ & $8,737,883$ & $0.25[0.21 ; 0.29]$ & $0.19[0.16 ; 0.22]$ & 53,938 \\
\hline A02BC03 - Lansoprazole & $161(3.3)$ & $900,407,668$ & $6,889,923$ & $0.18[0.15 ; 0.21]$ & $0.23[0.20 ; 0.27]$ & 42,795 \\
\hline A02BX13 - Alginic acid & $154(3.2)$ & $299,064,119$ & $7,628,487$ & $0.51[0.43 ; 0.61]$ & $0.20[0.17 ; 0.24]$ & 49,536 \\
\hline M01AE03 - Ketoprofen & $153(3.2)$ & $813,655,782$ & $18,897,000$ & $0.19[0.16 ; 0.22]$ & $0.08[0.07 ; 0.10]$ & 123,510 \\
\hline
\end{tabular}


Table 3. Top 25 drugs (ATC code, ingredients) dispensed within 7-60 days before hospital admission for ALI with the highest ratios of exposed cases to exposed population between 2010 and 2014

\begin{tabular}{|c|c|c|c|c|c|}
\hline & $\begin{array}{c}\text { Number of } \\
\text { ALI }\end{array}$ & Number of patients & $\begin{array}{c}\text { Number of cases } \\
\text { per } 10000 \text { users }[95 \% \mathrm{CI}]\end{array}$ & $\begin{array}{c}\text { Number of } \\
\text { users per case }\end{array}$ & $\begin{array}{l}\text { Case-population } \\
\text { ratio (users) }\end{array}$ \\
\hline All cases/reference population & 4807 & $65,375,384$ & 0.73 & 13,600 & 1.00 \\
\hline J04AM05 Rifampicin, pyrazinamide and isoniazid & 35 & 20,247 & $17.3[12.0 ; 24.0]$ & 578 & $23.5[16.8-32.7]$ \\
\hline J04AK01 - Pyrazinamide & 10 & 7,702 & $13.0[6.23 ; 23.9]$ & 770 & $17.7[9.50-32.8]$ \\
\hline J04AK02 - Ethambutol & 27 & 22,268 & $12.1[7.99 ; 17.6]$ & 825 & $16.5[11.3-24.1]$ \\
\hline J04AC01 - Isoniazid & 14 & 17,940 & $7.8[4.26 ; 13.09]$ & 1,281 & $10.6[6.28-17.9]$ \\
\hline J04AM02 - Rifampicin and isoniazid & 31 & 59,782 & $5.2[3.52 ; 7.36]$ & 1,928 & $7.1[4.96-10.0]$ \\
\hline C10AC01 - Colestyramine & 30 & 159,373 & $1.9[1.27 ; 2.69]$ & 5,312 & $2.6[1.79-3.66]$ \\
\hline J01FA01 - Erythromycin & 56 & 300,937 & $1.9[1.41 ; 2.42]$ & 5,374 & $2.5[1.95-3.29]$ \\
\hline J04AB02 - Rifampicin & 22 & 139,309 & $1.6[0.99 ; 2.39]$ & 6,332 & $2.1[1.41-3.26]$ \\
\hline C01BG07 - Cibenzoline & 5 & 32,261 & $1.5[0.50 ; 3.62]$ & 6,452 & $2.1[0.88-5.06]$ \\
\hline C02AB02 - Methyldopa (racemic) & 10 & 67,189 & $1.5[0.71 ; 2.73]$ & 6,719 & $2.0[1.09-3.76]$ \\
\hline N03AF02 - Oxcarbazepine & 9 & 71,005 & $1.3[0.58 ; 2.41]$ & 7,890 & $1.7[0.90-3.31]$ \\
\hline N03AA02 - Phenobarbital & 17 & 137,193 & $1.2[0.72 ; 1.98]$ & 8,070 & $1.7[1.05-2.71]$ \\
\hline N03AF01 - Carbamazepine & 41 & 340,863 & $1.2[0.86 ; 1.63]$ & 8,313 & $1.6[1.20-2.22]$ \\
\hline N06AB08 - Fluvoxamine & 5 & 42,395 & $1.2[0.38 ; 2.75]$ & 8,479 & $1.6[0.67-3.85]$ \\
\hline N03AG01 - Valproic acid & 71 & 645,763 & $1.1[0.86 ; 1.39]$ & 9,095 & $1.5[1.18-1.89]$ \\
\hline N03AX09 - Lamotrigine & 27 & 245,831 & $1.1[0.72 ; 1.60]$ & 9,105 & $1.5[1.02-2.18]$ \\
\hline C01DA14 - Isosorbide mononitrate & 8 & 73,373 & $1.1[0.47 ; 2.15]$ & 9,172 & $1.5[0.74-2.97]$ \\
\hline C07AG02 - Carvedilol & 5 & 50,409 & $0.99[0.32 ; 2.32]$ & 10,082 & $1.3[0.56-3.24]$ \\
\hline B01AA07 - Acenocoumarol & 21 & 221,980 & $0.95[0.59 ; 1.45]$ & 10,570 & $1.3[0.84-1.97]$ \\
\hline B01AA03 - Warfarin & 36 & 400,734 & $0.90[0.63 ; 1.24]$ & 11,362 & $1.2[0.88-1.69]$ \\
\hline C07AB05 - Betaxolol & 13 & 147,703 & $0.88[0.47 ; 1.51]$ & 11,362 & $1.2[0.70-2.06]$ \\
\hline N06DA03 - Rivastigmine & 20 & 229,195 & $0.87[0.53 ; 1.35]$ & 11,460 & $1.2[0.77-1.84]$ \\
\hline N06DX01 - Memantine & 27 & 311,492 & $0.87[0.57 ; 1.26]$ & 11,537 & $1.2[0.81-1.72]$ \\
\hline C09AA01 - Captopril & 8 & 93,556 & $0.86[0.37 ; 1.68]$ & 11,695 & $1.2[0.58-2.33]$ \\
\hline N06DA04 - Galantamine & 10 & 119,721 & $0.84[0.40 ; 1.54]$ & 11,972 & $1.1[0.61-2.11]$ \\
\hline
\end{tabular}

ALI. Acute Liver Injury ATC: anatomical chemical therapeutic classification of medicines.

Case-population ratio: ratio of exposure in cases to exposure in the reference population in number of patients exposed. 
Table 4. Top 25 drugs (ATC Code, ingredients) dispensed within 7-60 days before hospital admission for ALI with the highest ratio of exposed cases to patient exposure (in DDD) between 2010 and 2014

\begin{tabular}{|c|c|c|c|c|c|c|}
\hline & $\begin{array}{c}\text { Number } \\
\text { of ALI }\end{array}$ & $\begin{array}{c}\text { Number of DDD } \\
\text { dispensed }\end{array}$ & $\begin{array}{l}\text { Average treatment } \\
\text { duration (days) }\end{array}$ & $\begin{array}{c}\text { Number of cases per } \\
\text { million DDD (for } 5 \text { years) }\end{array}$ & $\begin{array}{l}\text { Million DDD } \\
\text { per case }\end{array}$ & $\begin{array}{l}\text { Case-population } \\
\text { ratio (DDD)* }\end{array}$ \\
\hline All cases/reference population & 4807 & $119,310,075,800$ & & 0.04 & 24.8 & 1 \\
\hline J04AM05 - Rifampicin, pyrazinamide and isoniazid & 35 & $1,178,553$ & 58.21 & $29.7[20.7 ; 41.3]$ & 0.034 & $737.1[528.6-1027.8]$ \\
\hline J04AK01 - Pyrazinamide & 10 & 654,693 & 85 & $15.3[7.33 ; 28.1]$ & 0.065 & $379.1[203.8-705.1]$ \\
\hline J04AK02 - Ethambutol & 27 & $2,120,578$ & 95.23 & $12.7[8.39 ; 18.5]$ & 0.079 & $316.0[216.5-461.3]$ \\
\hline J01FA01 - Erythromycin & 56 & $7,076,693$ & 23.52 & $7.9[5.98 ; 10.3]$ & 0.126 & $196.4[151.0-255.8]$ \\
\hline J04AM02 Rifampicin and isoniazid & 31 & $5,929,932$ & 99.19 & $5.2[3.55 ; 7.42]$ & 0.191 & $129.8[91.2-184.8]$ \\
\hline J04AC01 - Isoniazid & 14 & $3,061,062$ & 170.63 & $4.6[2.50 ; 7.67]$ & 0.219 & $113.6[67.2-191.9]$ \\
\hline R06AD08 - Oxomemazine & 82 & $18,262,910$ & 1.92 & $4.5[3.57 ; 5.57]$ & 0.223 & $111.5[89.7-138.7]$ \\
\hline A02BD08 - Bismuth, tetracycline and metronidazole & 5 & $1,303,065$ & 10.34 & $3.8[1.24 ; 8.96]$ & 0.261 & $95.3[39.6-229.1]$ \\
\hline J01XX01 - Fosfomycin & 58 & $15,514,861$ & 2.94 & $3.7[2.84 ; 4.83]$ & 0.267 & $92.9[71.7-120.3]$ \\
\hline J01DD04 - Ceftriaxone & 37 & $12,088,318$ & 6.03 & $3.1[2.15 ; 4.22]$ & 0.327 & $76.0[55.0-105.1]$ \\
\hline J01DC07 - Cefotiam & 10 & $4,225,146$ & 3.92 & $2.4[1.14 ; 4.35]$ & 0.423 & $58.9[31.6-109.3]$ \\
\hline J01MA07 - Lomefloxacin & 14 & $7,601,244$ & 4.45 & $1.8[1.01 ; 3.09]$ & 0.543 & $45.8[27.1-77.3]$ \\
\hline J04AB02 - Rifampicin & 22 & $12,357,882$ & 88.71 & $1.8[1.12 ; 2.70]$ & 0.562 & $44.2[29.1-67.2]$ \\
\hline C02AB02 - Methyldopa (racemic) & 10 & $5,944,899$ & 88.48 & $1.7[0.81 ; 3.09]$ & 0.594 & $41.9[22.5-77.7]$ \\
\hline C10AC01 - Colestyramine & 30 & $18,169,739$ & 114.01 & $1.6[1.11 ; 2.36]$ & 0.606 & $41.0[28.6-58.7]$ \\
\hline J01FF01 - Clindamycin & 10 & $6,489,170$ & 20.37 & $1.5[0.74 ; 2.83]$ & 0.649 & $38.3[20.6-71.2]$ \\
\hline J01XC01 - Fusidic acid & 10 & $7,554,527$ & 8.34 & $1.3[0.64 ; 2.43]$ & 0.755 & $32.9[17.7-61.1]$ \\
\hline J01EE01 - Sulfamethoxazole and trimethoprim & 53 & $42,279,776$ & 20.78 & $1.3[0.94 ; 1.64]$ & 0.798 & $31.1[23.7-40.8]$ \\
\hline J01FA02 - Spiramycin & 14 & $12,660,637$ & 8.85 & $1.1[0.60 ; 1.86]$ & 0.904 & $27.5[16.3-46.4]$ \\
\hline J01FA15 - Telithromycin & 7 & $6,422,211$ & 9.08 & $1.1[0.44 ; 2.25]$ & 0.917 & $27.1[12.9-56.8]$ \\
\hline A02AB03 - Aluminium phosphate & 7 & $6,753,221$ & 17.63 & $1.0[0.42 ; 2.14]$ & 0.965 & $25.7[12.3-54.0]$ \\
\hline J01FA07 - Josamycin & 18 & $17,985,220$ & 10.53 & $1.0[0.59 ; 1.58]$ & 0.999 & $24.9[15.7-39.5]$ \\
\hline J01XE01 - Nitrofurantoin & 29 & $29,633,830$ & 18.41 & $0.98[0.66 ; 1.41]$ & 1.022 & $24.3[16.9-35.0]$ \\
\hline J01MA02 - Ciprofloxacin & 52 & $54,450,964$ & 14.34 & $0.95[0.71 ; 1.25]$ & 1.047 & $23.7[18.1-31.2]$ \\
\hline J01MA06 - Norfloxacin & 50 & $53,321,277$ & 13.09 & $0.94[0.70 ; 1.24]$ & 1.066 & $23.3[17.6-30.8]$ \\
\hline
\end{tabular}

ALI: acute liver injury; DDD: Defined daily dose; * Case-population ratio: ratio of exposure in cases compared to whole population, in DDD (person-time) 


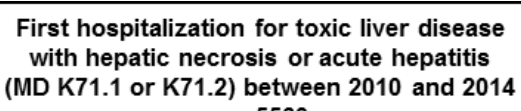

First hospitalization for toxic liver disease with hepatitis not elsewhere classified or toxic liver disease unspecified (MD K71.6 or K71.9) between 2010 and 2014 $n=2566$

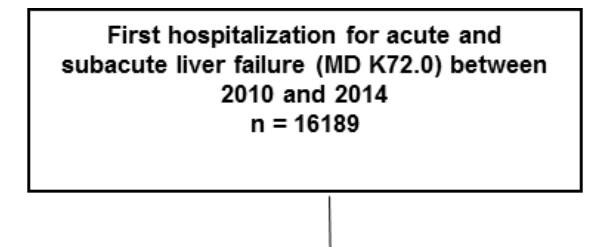

Patients without health consumption in the SNDS database, $n=162$

- Patients $<18$ years, $n=760$

Patients not affiliated to the national healthcare insurance system during the year of hospitalization of interest, $n=2285$

- Patients with no history or with less than 60 days of history in the healthcare consumption data before hospitalization of interest, $n=1082$

- Patients with previous hospitalization for ALI, $n=116$

- Patients with at least one associated, related or main diagnosis of a liver disease or a potential liver damage in the 60 days before the hospitalization of interest or during the hospitalization of interest, $n=1298$

Patients with previous hospitalization of liver transplant in the previous 60 days, $\mathrm{n}=5$

- Patients with a hospitalization of interest with a DRG code including endoscopies, diagnostic procedures, or HIV disease, $n=105$

- Patients with a previous hospitalization with a DRG code including alcoholic cirrhosis, chronic hepatitis, alcoholics or malignant neoplasm (pancreas or hapatobiliary), $n=163$

- Patients with previous hospitalization ended in the 30-days period before the hospitalization of interest, $n=1123$

Patients with previous hospitalization started $>7$ days before the hospitalization of interest and ended on the same date or after the hospitalization of interest, $n=29$

- Patients with at least one diagnostic code of poisoning during the hospitalization of interest, $n=697$

Figure 1. Flow chart of adult ALI cases identification between 2010-2014.

ALI: Acute liver injury; DRG: Diagnosis related group; ICD: International Classification of Diseases 10th revision; MD:

main diagnosis, SNDS: Système National des Données de Santé 


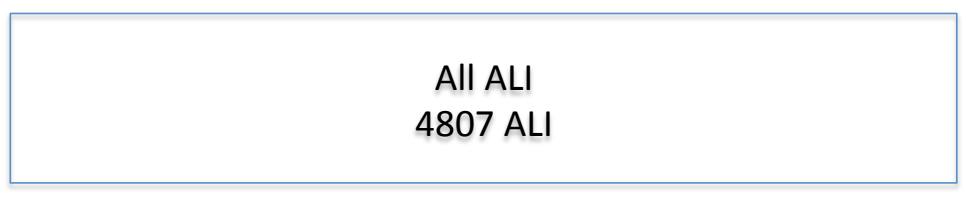

At least 1 exposure 0-60 days before index date $4245 \mathrm{ALI}$

At least 1 drug exposure 7-60 days before ID
3877 ALI

\begin{tabular}{|c|}
\hline$\geq 1$ exposure $7-60$ days \\
to drugs with $\geq 5$ exposed cases \\
3633 ALI \\
249 drugs \\
\hline
\end{tabular}

Figure 2: selection of hospitalisations for acute liver injury

ALI: Acute liver injury; ID: Index date 


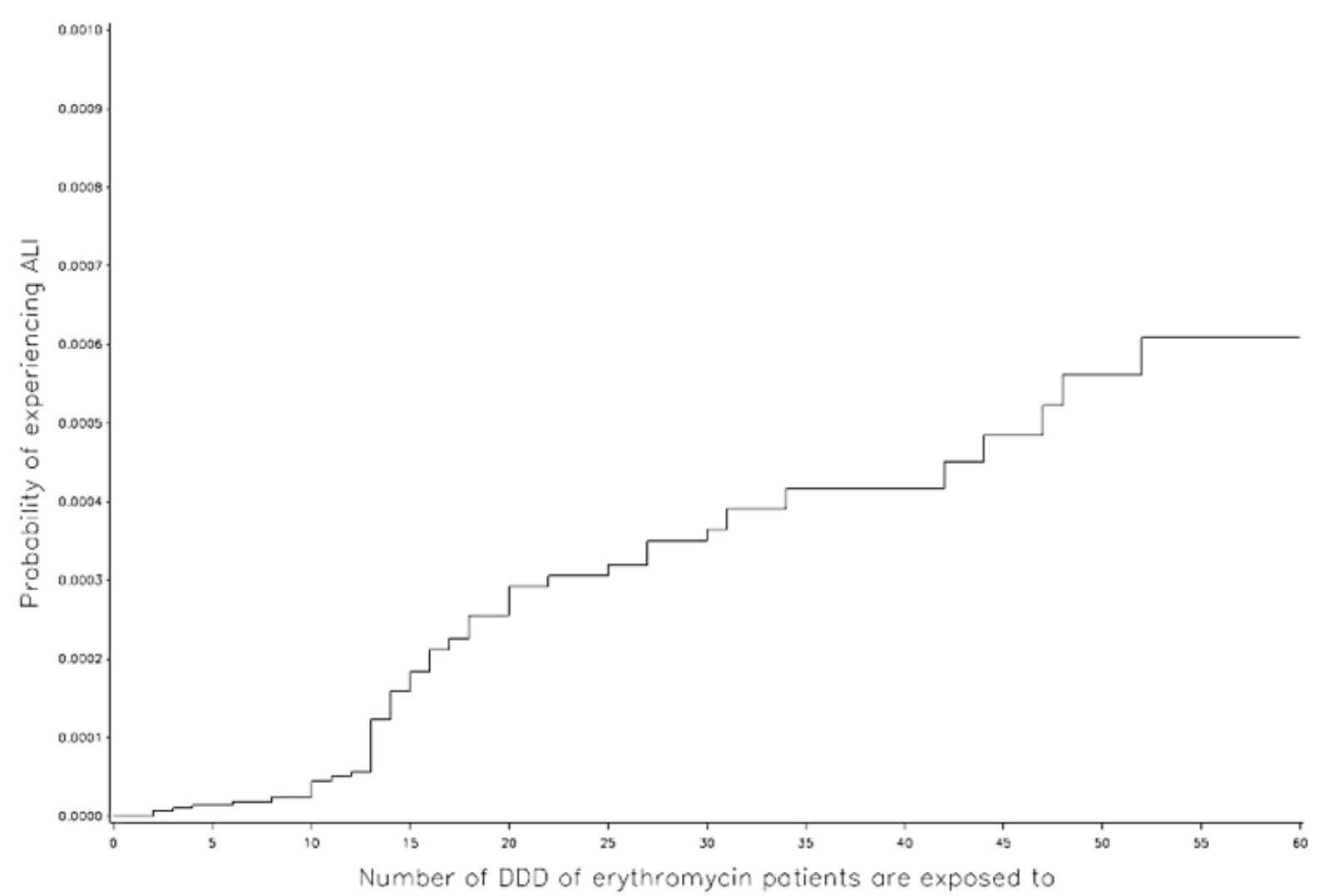

Figure 3. Cumulative incidences for erythromycin according to the number of DDD dispensed in cases and in the extrapolated reference population between 2010-2014.

DDD: Defined daily dose 


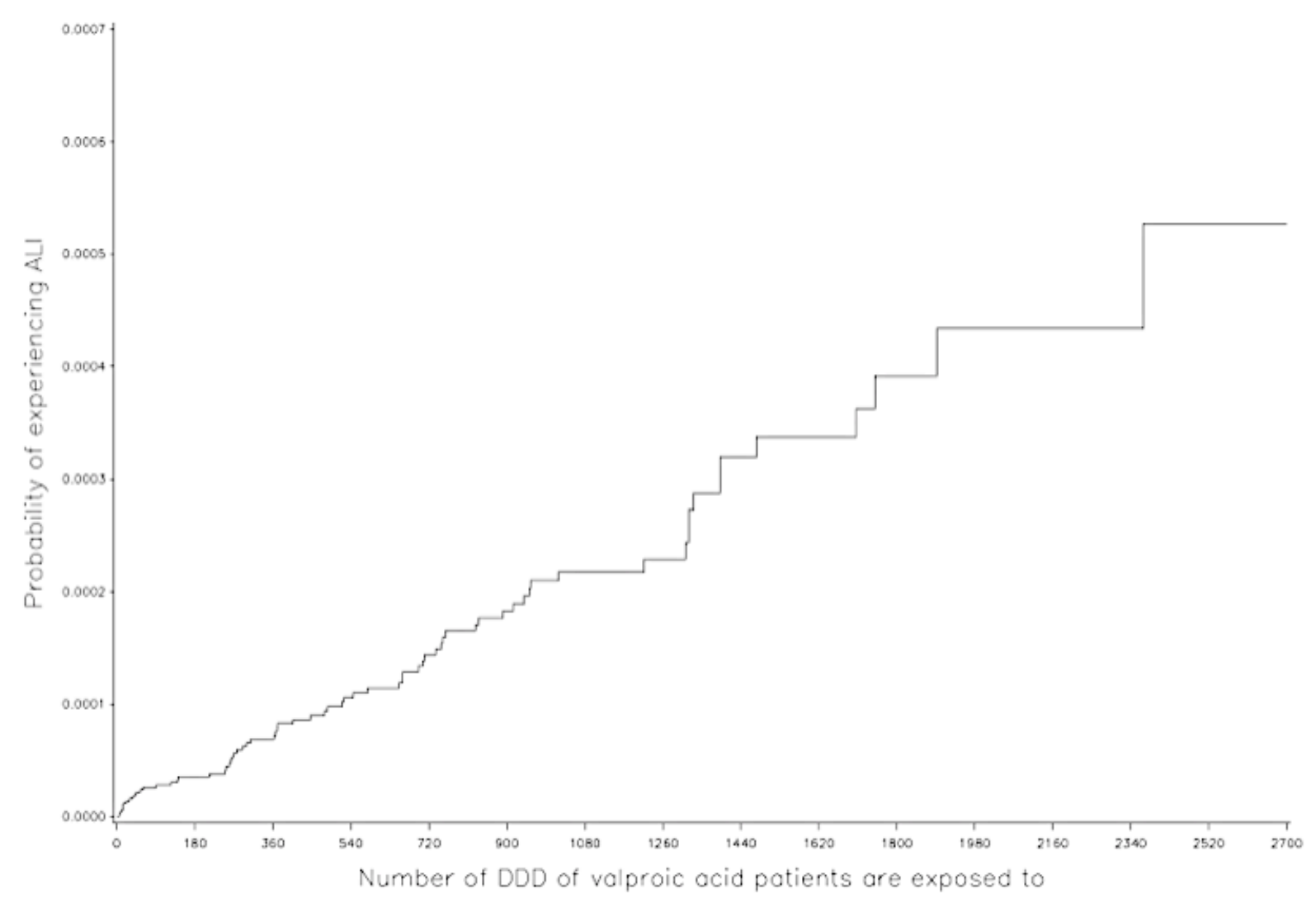

Figure 4. Cumulative incidences for valproic acid according to the number of DDD dispensed in cases and in the extrapolated reference population between 2010-2014.

DDD: Defined daily dose 